\title{
Removal of Azo Dyes (Violet B and Violet 5R) from Aqueous Solution Using New Activated Carbon Developed from Orange Peel
}

\author{
Saeedeh Hashemian, ${ }^{1}$ Khaterah Salari, ${ }^{1}$ Hamila Salehifar, ${ }^{2}$ and Zahra Atashi Yazdi ${ }^{1}$ \\ ${ }^{1}$ Chemistry Department, Islamic Azad University, Yazd Branch, Yazd, Iran \\ ${ }^{2}$ Computer Department, College of Engineering, Islamic Azad University, Yazd Branch, Yazd, Iran \\ Correspondence should be addressed to Saeedeh Hashemian; sa_hashemian@yahoo.com
}

Received 25 May 2013; Revised 13 August 2013; Accepted 23 September 2013

Academic Editor: Shayessteh Dadfarnia

Copyright (c) 2013 Saeedeh Hashemian et al. This is an open access article distributed under the Creative Commons Attribution License, which permits unrestricted use, distribution, and reproduction in any medium, provided the original work is properly cited.

\begin{abstract}
Activated carbon developed from agricultural waste orange peel (COP) was prepared. COP was characterized using Fourier infrared spectroscopy (FTIR), X-ray powder diffraction (XRD), scanning electron microscopy (SEM), and BET. COP has surface area and mean pore diameter of $225.6 \mathrm{~m}^{2} \mathrm{~g}^{-1}$ and $22.40 \mathrm{~nm}$, respectively. The removal of violet $\mathrm{B}(\mathrm{VB})$ and violet $5 \mathrm{R}$ (V5R) from aqueous solutions by COP was investigated. The effect of operational parameters such as contact time, $\mathrm{pH}$, initial dye concentration, and adsorbent dosage on the adsorption of dyes was investigated. Maximum dye was removed within $30 \mathrm{~min}$ of contact time at $\mathrm{pH}>$ 7. Two common models, the Langmuir and Freundlich isotherms, were used to investigate the interaction of dye and COPs. The isotherm evaluations revealed that the Langmuir model provides better fit to the experimental data than the Freundlich model. The adsorption of VB and V5R onto COP was followed by pseudo-second-order kinetic model with a good correlation $\left(R^{2}>0.99\right)$. Activation energies 5.47 and $29.7 \mathrm{KJ} \mathrm{mol}^{-1}$ were determined for violet $\mathrm{B}$ and violet $5 \mathrm{R}$, respectively. The rate of adsorption of violet $5 \mathrm{R}$ was faster than that of violet $\mathrm{B}\left(k_{\mathrm{V} 5 \mathrm{R}}>k_{\mathrm{VB}}\right)$. The prepared COP could thus be used as promising adsorbent for removal of organic dyes, especially azo dye, from polluted water. The solid COP could be conveniently regenerated after adsorption.
\end{abstract}

\section{Introduction}

Many industries employ dyes and pigments to color their products. Most dyes are inert and nontoxic at the concentration discharged into the receiving water. Dyes are usually stable to photodegradation, biodegradation, and oxidizing agents [1]. Color removal from effluents is a major environmental problem because of difficulty of treating such streams by conventional physicochemical and biological treatment methods [2]. Many physical and chemical methods such as coagulation, precipitation, and oxidation have been used for dye removal from water [3]. Adsorption has been described in order to eliminate or lower concentration of a wide range of dissolved pollutants (organic or inorganic) in the effluent [4]. Dye removal by different sorbents was evaluated $[5,6]$. Activated carbon is the most widely used adsorbent for this purpose. It has high capacity for adsorption of organic maters, but its uses are limited, because of its high cost $[7,8]$. This has led to search for cheaper sorbents such as mineral clays [9-12], sawdust [13-16], and so on. Recently, various kinds of activated carbon have been achieved from different agriculture wastes and used as low-cost sorbents for removal of heavy metals, organic compounds, and dyes from aqueous solution [17-20]. Orange, as a kind of biological resources, is available in large quantities in many parts of the world. The orange peel mainly consists of cellulose, hemicellulose, and lignin in the form of carboxyl and hydroxyl. Since the orange peel is available free of cost from orange processing industries, only the carbonization of it is involved for the waste for wastewater treatment would not only be economical but also will help to solve solid waste disposal problems [21-24].

The main objective of this work is possibility of using activated carbon from orange peels as a low-cost adsorbent for removal of violet $B$ and violet $5 R$ from aqueous solutions. 


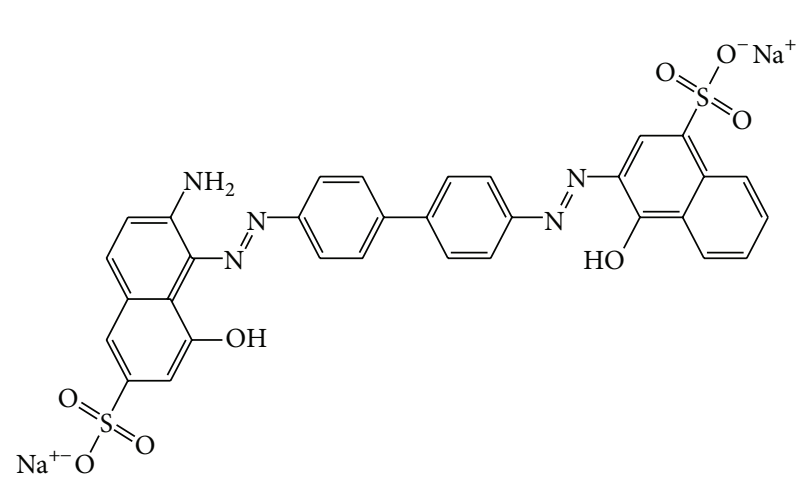

(a)

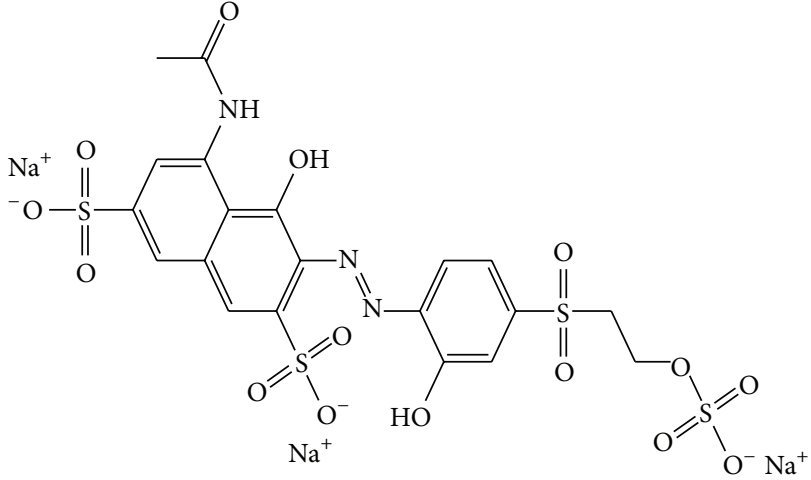

(b)

FIGURE 1: Chemical structure of (a) violet $B$ and (b) violet $5 R$.

The effects of important experimental parameters such as contact time, initial dye concentration, adsorbent concentration, and ionic strength were studied. The adsorption kinetics and isotherms were described.

\section{Experimental}

2.1. Material and Method. Orange peels were collected from a local fruit field in the south of Iran. The collected biomaterial was extensively washed under tap water to remove any particulate sprayed with distilled water (OP). Then, they were dried in oven at $100^{\circ} \mathrm{C}$ for $24 \mathrm{~h}$ and were sieved. After sieving the particle size of materials was remained between 1 and $5 \mathrm{~mm}$.

Violet $\mathrm{B}(\mathrm{VB})$ and violet $5 \mathrm{R}(\mathrm{V} 5 \mathrm{R})$ were obtained from Merck. The stock solution of $1000 \mathrm{mg} \mathrm{L}^{-1}$ of VB and V5R was prepared. The dilution was done in water when necessary. All chemicals were analytical grade reagents from Merck and were used without any purification.

2.2. Preparation of the Adsorbent or COP. Activated carbon from orange peel was prepared. The orange peel sample biomass $500.0 \mathrm{~g}$ was added in small portion to $1.0 \mathrm{~L}$ of $98 \%$ $\mathrm{H}_{2} \mathrm{SO}_{4}$ during $6 \mathrm{~h}$ and resulting reaction mixture was cut into small pieces. They were air-dried in an oven at $100-120^{\circ} \mathrm{C}$ for $24 \mathrm{~h}$. Activated carbons were carried out in a muffle furnace. A crucible was cleaned and heated to a constant weight. The orange paste was then transferred into the crucible and latter was placed in the furnace. The orange paste was activated at $700^{\circ} \mathrm{C}\left(5^{\circ} \mathrm{C} / \mathrm{min}\right)$ for $3 \mathrm{~h}$. The activated product was cooled down to room temperature, washed with distilled water, and then dried in the oven at $100^{\circ} \mathrm{C}$ for $6 \mathrm{~h} \mathrm{[24].}$

2.3. Adsorbate Preparation. 1-Naphthalenesulfonic acid, 3((4'-((2-amino-8-hydroxy-6-sulfo-1-naphthalenyl)azo)(1,1' biphenyl)-4-yl)azo)-4-hydroxy-, disodium salt (violet B) and 5-(Acetylamino)-4-hydroxy-3-[[2-hydroxy-4-[[2-(sulfooxy)ethyl]sulfonyl]phenyl]azo]-2,7-naphthalenedisulfonic acid trisodium salt (violet $5 \mathrm{R}$ ) as pollutant models were used. Violet $\mathrm{B}$ is double azo class with molecular formula of $\mathrm{C}_{32} \mathrm{H}_{21} \mathrm{~N}_{5} \mathrm{Na}_{2} \mathrm{O}_{8} \mathrm{~S}_{2}$ (MW = 713.65). Violet $5 \mathrm{R}$ is mono azo class with molecular formula of $\mathrm{C}_{20} \mathrm{H}_{16} \mathrm{~N}_{3} \mathrm{O}_{15} \mathrm{~S}_{4} \mathrm{Na}_{3}$ (MW = 735.58).

A stock solution of $1000 \mathrm{mg} \mathrm{L}^{-1}$ of each dye was prepared in double distilled water. It is subsequently whenever necessary diluted. Chemical structure of violet $B$ and violet $5 R$ is shown in Figure 1.

Adsorption studies were carried out in glass vessels with agitation provided by a shaker. The temperature was controlled at $25^{\circ} \mathrm{C}$ by air bath. The suspensions containing $0.1 \mathrm{~g}$ COP and varying amounts of dyes were shaken on an orbital shaker at $150 \mathrm{rpm}$. Samples for the kinetic study were taken at different time intervals. For adsorption experiments, $50 \mathrm{~mL}$ dye solution $\left(50-150 \mathrm{mg} \mathrm{L}^{-1}\right)$ and $0.1 \mathrm{~g}$ of COP were used. The effect of $\mathrm{pH}$ was studied by adjusting of $\mathrm{pH}$ of the solutions in the range of 2-12 with $0.1 \mathrm{~N} \mathrm{NaOH}$ or $\mathrm{HCl}$ solutions. Samples were withdrawn at appropriate time intervals and centrifuged at $3000 \mathrm{rpm}$ for $5 \mathrm{~min}$ and the absorbance of the supernatant was measured using a UV-vis spectrophotometer (Shimadzu 160-A, Japan) at $\lambda_{\max }$ of each dye. The results are average as at least 3 experiments.

Kinetics of adsorption was determined by analyzing sorptive uptake of the dye from aqueous solution at different time intervals. For sorption isotherms determination, dye solutions of different concentrations were agitated with known amount of sorbents till the equilibrium was achieved at room temperature $\left(25^{\circ} \mathrm{C}\right)$.

IR measurements were performed by FTIR tensor-27 of Burker Co. Pressed pellets were prepared by grinding the powder specimens with spectroscopic grade $\mathrm{KBr}$ for FTIR spectra test. All pH measurements were carried out with an ISTEK-720P pH meter. Scanning electron microscopy was performed using a Philips SEM model XL30 electron microscope. The powder X-ray diffraction studies were made on Philips PW3719 X-ray diffractometer by using $\mathrm{Cu}-\mathrm{K}_{\alpha}$ radiation of wave length $1.54060 \AA$. The specific surface area was measured by $\mathrm{N}_{2}$ adsorption-desorption isotherm and was obtained with an ASAP 2010 instrument (Micromeritics).

The percent removal of violet $B$ and violet $5 R$ by the hereby adsorbent is given by

$$
\text { \%Removal }=\frac{C_{0}-C_{e}}{C_{0} \times 100},
$$


TABLE 1: Characterization of OP and COP.

\begin{tabular}{lcccc}
\hline Sample & Sample weight $(\mathrm{g})$ & Mean pore diameter $(\mathrm{nm})$ & Total pore volume $\left(\mathrm{cm}^{3} \mathrm{~g}^{-1}\right)$ & Surface $\operatorname{area}\left(\mathrm{m}^{2} \mathrm{~g}^{-1}\right)$ \\
\hline OP & 0.1920 & 13.56 & 6.92 & 22.4 \\
COP & 0.1915 & 22.40 & 14.5 & 225.6 \\
\hline
\end{tabular}

where $C_{0}, C_{e}$ denotes the initial and equilibrium dye concentration $\left(\mathrm{mg} \mathrm{L}^{-1}\right)$. The amount of dye adsorbed $\left(q_{e}\right)$ was determined by using the following equation:

$$
q_{e}=\frac{\left(C_{0}-C_{e}\right) V}{m},
$$

where $V$ is the volume of the solutions $(\mathrm{mL})$ and $m$ is the amount (mg) of adsorbent.

\section{Results and Discussion}

3.1. Characterization of Adsorbent. FTIR spectra of OP, COP and activated carbon (Merck) are shown in Figure 2. In OP spectrum (Figure 2(a)) the broad and intense adsorption peaks at around $3400 \mathrm{~cm}^{-1}$ correspond to $\mathrm{O}-\mathrm{H}$ stretching vibrations due to inter and inter-molecular hydrogen banding of polymeric compounds (macromolecular associations), such as alcohols, phenols and carboxylic acids, as in pectin, cellulose groups on the adsorbent surface. The peaks at $2924 \mathrm{~cm}^{-1}$ are attributed to the symmetric and asymmetric $\mathrm{C}-\mathrm{H}$ stretching vibration of aliphatic acids. The peak observed at $1751 \mathrm{~cm}^{-1}$ is the stretching vibration of bond due to nonionic carboxyl groups $\left(-\mathrm{COOH},-\mathrm{COOCH}_{3}\right)$ and may be assigned to carboxylic acids or their esters. Peaks at 1000$1080 \mathrm{~cm}^{-1}$ may be due to stretching vibration of $\mathrm{C}-\mathrm{OH}$ of alcoholic groups and carboxylic acids. The peak observed at $1618 \mathrm{~cm}^{-1}$ is due to $\mathrm{C}=\mathrm{C}$ stretching that can be attributed to the aromatic $\mathrm{C}-\mathrm{C}$ bond. The peaks observed at $623 \mathrm{~cm}^{-1}$ correspond to the $\mathrm{C}-\mathrm{C}$ group [25]. Figure 2(b) shows that the prepared activated carbon from orange peel. It shows the functional groups of surface of orange peel disappeared. Figure 2(c) shows the activated carbon from Merck. Comparing Figures 2(b) and 2(c) confirmed the activated carbon from orange peel.

The FTIR spectra of COP and dye loaded COP was illustrated in Figures 2(d) and 2(e), in order to compare the differences among them with COP. From Figures 2(d) and 2(e), the broad bonds at $3400-3600 \mathrm{~cm}^{-1}$ and $3300-3450 \mathrm{~cm}^{-1}$ correspond to $\mathrm{O}-\mathrm{H}$ stretching vibrations of violet $5 \mathrm{R}$ loaded $\mathrm{COP}$ and violet $\mathrm{B}$ loaded $\mathrm{COP}$, respectively. The appearance of bonds at 1000-2200 in Figures 2(d) and 2(e) also shows the presence of dye on the surface of COP. From the results, presence of functional groups of dyes was observed at FTIR of them and COP acts as a good sorbent.

SEM image of COP before and after adsorption of VB shows in Figure 3. The SEM image is shown the porous nature of COP. The COP has cylindrical porous shape and homogeneous distribution with mean pore diameter $22.40 \mathrm{~nm}$. The COP particles have surface area of $225.6 \mathrm{~m}^{2} \mathrm{~g}^{-1}$ and total pore volume $14.5 \mathrm{~cm}^{3} \mathrm{~g}^{-1}$ (Table 1). After adsorption of dye, a significant change was observed in structure of surface of carbon orange peels. The peels appear to have a rough surface because they are covered by dye molecules.

X-ray diffraction patterns for activated carbon and COP are shown in Figure 4 . The positions of the peaks due to $d_{002}$ and $d_{100}$ reflections are attributed to $2 \theta=25.1^{\circ}$ and $45^{\circ}$, respectively [26]. These diffraction peaks are evidence that the samples have a turbostratic structure. This turbostratic model assumes that the sample is made of graphite-like microcrystallites, bounded by cross linking network, consisting of several graphite-like layers, stacked nearly parallel and equidistant, with each layer having a random orientation. The value of $d_{002}$ is comparable with those reported by Kumar et al. on activated carbon cloth [27].

3.2. Effect of Contact Time. Equilibrium time is important parameter for wastewater treatment process. The relation between removal of violet $B$ and violet $5 R$ and reaction time were studied. Figure 5 shows the percentage removal of violet $\mathrm{B}$ and violet $5 \mathrm{R}$ on comparison with activated carbon from Merck at different contact times. The adsorption increases with increasing of contact time. Obviously, the adsorption equilibrium was attained after stirring for $60 \mathrm{~min}$. It was found that more than $70 \%$ removal of violet B and $75 \%$ removal of violet $5 \mathrm{R}$ occurred in the first $30 \mathrm{~min}$ of contact time, and thereafter the rate of adsorption was found to be slow. The rapid adsorption at the initial contact time is due to the availability of the porosity surface of COP adsorbent which led to fast adsorption of dyes. Therefore, the fast adsorption rate reflects good accessibility of the binding sites of the COP for violet $B$ and violet $5 \mathrm{R}$. This has practical advantages in terms of reducing reactor volumes and time. The later slow rate of adsorption has probably occurred due to the slow pore diffusion of the solute ion into the bulk of the adsorbent. The equilibrium was found to be nearly 60 min when the maximum dye adsorption capacity was reached. Therefore, the adsorption time was fixed at $60 \mathrm{~min}$ in subsequent adsorption experiments. The results also showed that the COP can act as activated carbon for removal of dyes.

3.3. Effect of $\mathrm{pH}$ on Violet $B$ and Violet $5 \mathrm{R}$ Uptake. The $\mathrm{pH}$ of the system is very effective on the adsorption capacity of adsorbate molecule presumably due to its influence on the surface properties of the adsorbent and ionization/dissociation of the adsorbate molecule. Figure 6 shows the effect of $\mathrm{pH}$ on the removal of violet $\mathrm{B}$ and violet $5 \mathrm{R}$ from aqueous solution by COP. Effect of $\mathrm{pH}$ on adsorption of violet $\mathrm{B}$ and violet $5 \mathrm{R}$ onto $\mathrm{COP}\left(100 \mathrm{mg} \mathrm{L}^{-1}\right)$ was done at room temperature $\left(25 \pm 2^{\circ} \mathrm{C}\right)$, agitation speed $150 \mathrm{rpm}$ for the minimum contact time required to reach the equilibrium $(60 \mathrm{~min})$. With increasing in $\mathrm{pH}$ from 2 to 6 , the percent of dye removal increased from 69 to $90 \%$ and from 65 to $86 \%$ for V5R and VB, respectively. 


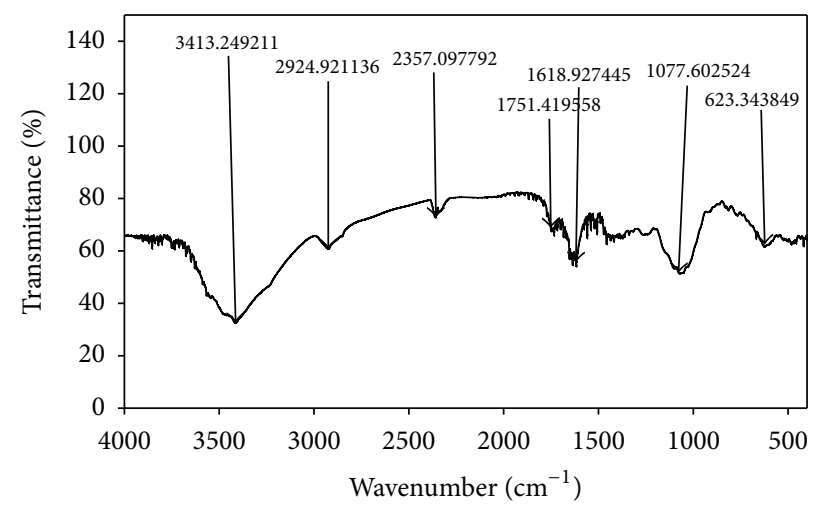

(a)

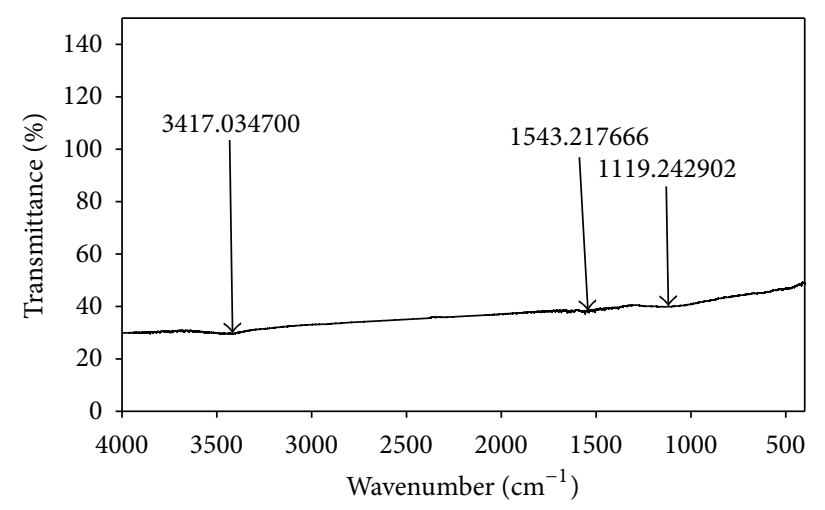

(c)

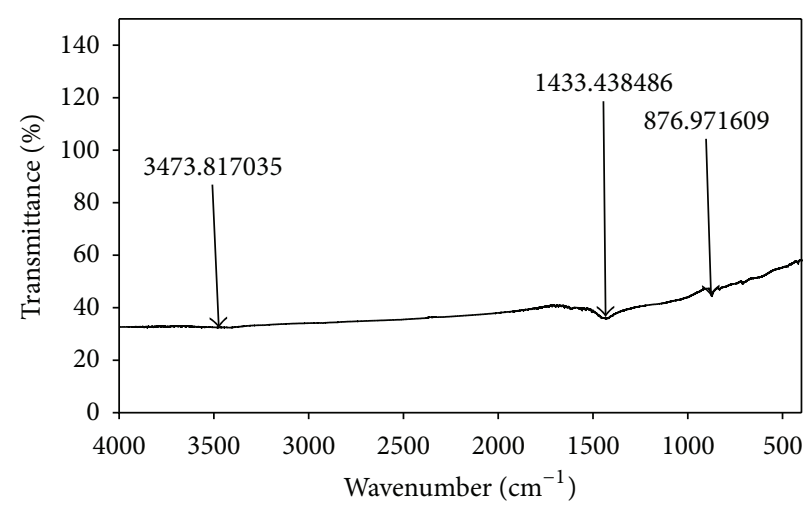

(b)

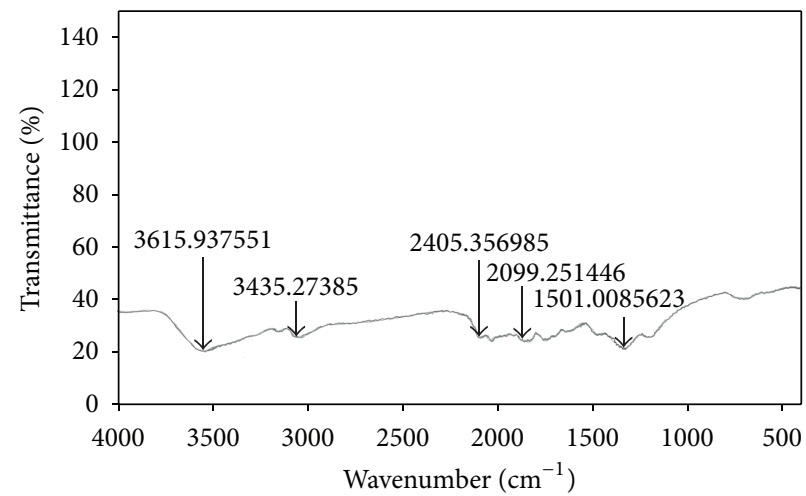

(d)

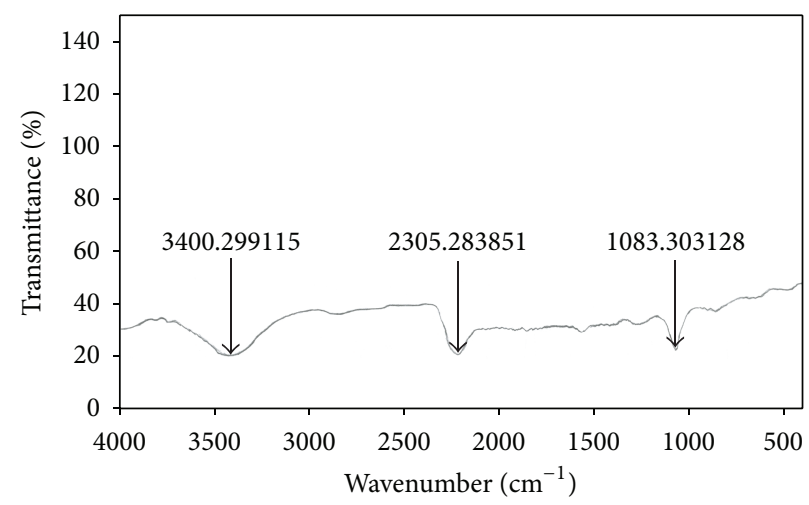

(e)

FIgURE 2: FTIR spectra of (a) OP, (b) COP, (c) activated carbon (Merck), (d) violet 5R loaded COP, and (e) violet B loaded COP.

However, two possible mechanisms of adsorption of dyes on COP adsorbent may be considered: (a) electrostatic interaction between the adsorbent and dye and (b) the chemical reaction between the dye and the adsorbent.

Low $\mathrm{pH}$ value (2.0-6.0) leads to an increase in $\mathrm{H}^{+}$ion concentration in the system and the surface of the COP acquires positive charge by absorbing $\mathrm{H}^{+}$ions (3). On the other hand, at low $\mathrm{pH}, \mathrm{H}^{+}$may compete with dye ions for adsorption sites of COP, thereby inhibiting the adsorption of dyes. As the COP surface is positively charged at low $\mathrm{pH}$ value, a significantly strong electrostatic repulsion appears between the sorbent surface and dye molecule leading to minimum adsorption of dyes. On the other hand, increase of the $\mathrm{pH}$ value (basic condition) led to increase of the number of negatively charged sites and the number of positively charged sites decreases as in (4). A negatively charged surface site on the COP dose is favoring adsorption of dye molecules due to the electrostatic attraction (5). The lowest adsorption 


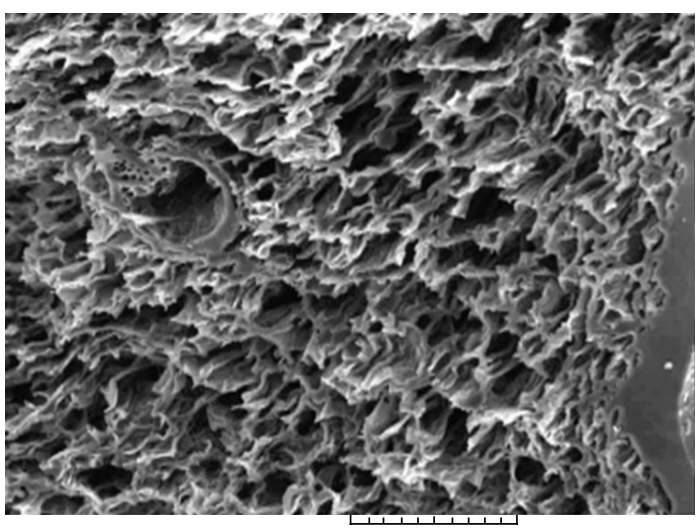

$100 \mu \mathrm{m}$

(a)

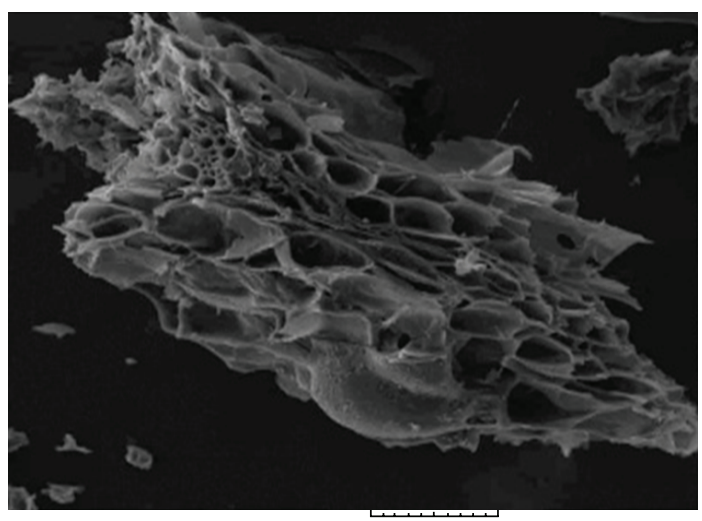

$100 \mu \mathrm{m}$

(c)

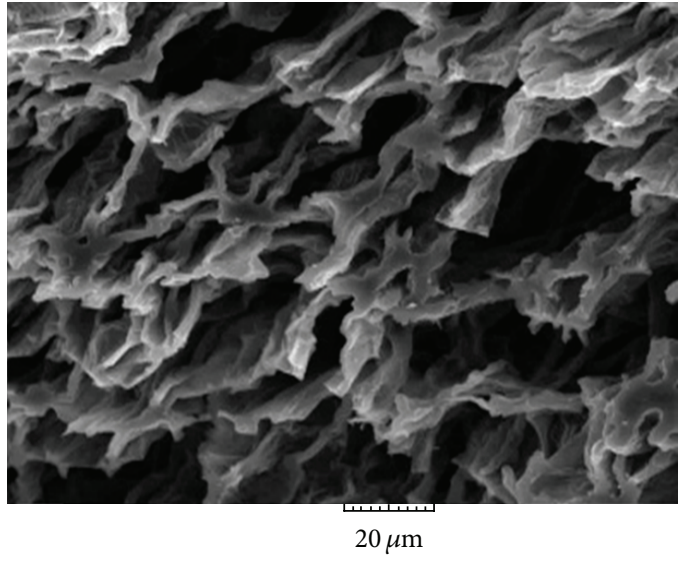

(b)

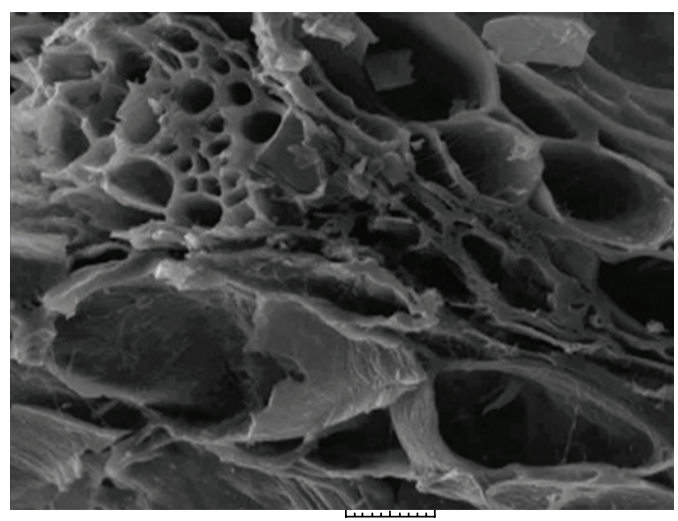

$20 \mu \mathrm{m}$

(d)

FIGURE 3: SEM image of COP (a), (b) before and (c), (d) after adsorption of VB.

occurred at $\mathrm{pH} 2.0$ and the greatest adsorption occurred at $\mathrm{pH}>7.0$. Therefore, optimum $\mathrm{pH}$ value $>7.0$ for dye adsorption was determined $[28,33]$

$$
\begin{gathered}
\mathrm{R}-\mathrm{OH}+\mathrm{H}^{+} \rightleftharpoons \mathrm{R}-\mathrm{OH}_{2}^{+} \\
\mathrm{R}-\mathrm{OH}+\mathrm{OH}^{-} \rightleftharpoons \mathrm{R}-\mathrm{O}^{-}+\mathrm{H}_{2} \mathrm{O} \\
\mathrm{R}-\mathrm{O}^{-}+\text {dye }{ }^{+} \rightleftharpoons \mathrm{R}-\mathrm{O}-\text { dye }
\end{gathered}
$$

From results of $\mathrm{pH}$ study and (3), (4), and (5), it seems that the mechanisms of adsorption were done by electrostatic interaction between COP and dyes.

3.4. Effect of Initial Dyes Concentration. The experimental results of the sorption of violet $B$ and violet $5 \mathrm{R}$ on COP at various initial dye concentrations are investigated. The experiments were carried out at adsorbate doses $0.4 \mathrm{~g} / 50 \mathrm{~mL}$ in the test solution, room temperature $\left(25 \pm 2^{\circ} \mathrm{C}\right)$ at different initial concentrations of violet $B$ and violet $5 R(50,75,100$, 125 and $150 \mathrm{mg} \mathrm{L}^{-1}$ ) for $60 \mathrm{~min}$. The percentage of adsorption efficiency was decreased with increasing of initial dye concentration in the solution [24]. However, the percentage removal of dye was greater at lower initial concentrations and smaller at higher initial concentrations. In the process of violet dyes adsorption initially dye molecules have to first encounter the boundary layer effect and then it has to diffuse from boundary layer film onto adsorbent surface and then finally it has to diffuse into the porous structure of the adsorbent. This phenomenon will take relatively longer contact time. These results clearly indicate that the adsorption of violet $\mathrm{B}$ and violet $5 \mathrm{R}$ from its aqueous solution was dependent on its initial concentration.

3.5. Effect of Adsorbent Mass on Dye Adsorption. The adsorption of violet $B$ and violet $5 \mathrm{R}$ on $\mathrm{COP}$ was studied by changing the mass of adsorbent $(0.05-2.0 \mathrm{~g} / 50 \mathrm{~mL})$ in the test solution at initial violet $B$ and violet $5 \mathrm{R}$ concentration $\left(100 \mathrm{mg} \mathrm{L}^{-1}\right)$, temperature $\left(25 \pm 2^{\circ} \mathrm{C}\right)$, and alkaline $\mathrm{pH}$ at contact time for $60 \mathrm{~min}$ (Figure 7). The percent of adsorption was increased and equilibrium time was decreased when adsorbent doses increased. The adsorption increased rapidly, when COP dose was increased from 0.05 to $0.5 \mathrm{~g} / 50 \mathrm{~mL}$ at equilibrium time 60 . This can be attributed to increasing of surface area of COP and availability of more adsorption sites [34].

3.6. Isotherm Data Analysis. Adsorption is usually described through an isotherm. The adsorption isotherm indicates how the adsorbed molecules distribute between the liquid phase 


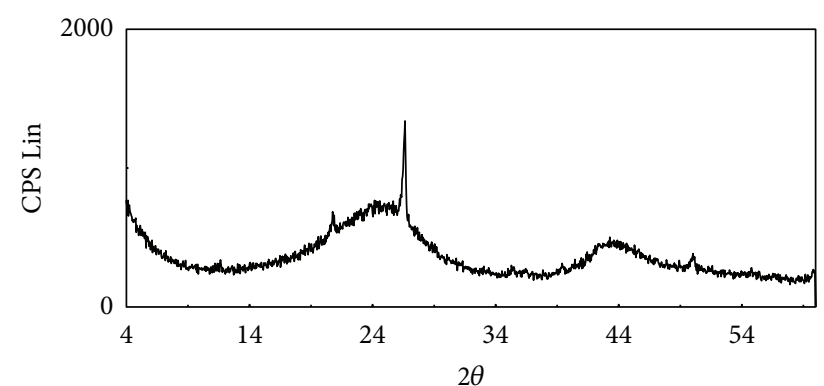

(a)

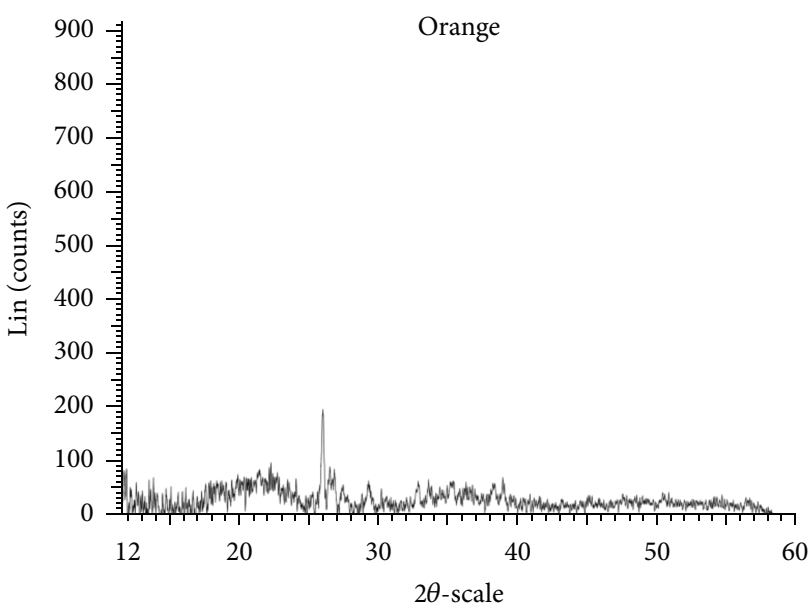

(b)

FIGURE 4: XRD patterns of (a) activated carbon and (b) COP.

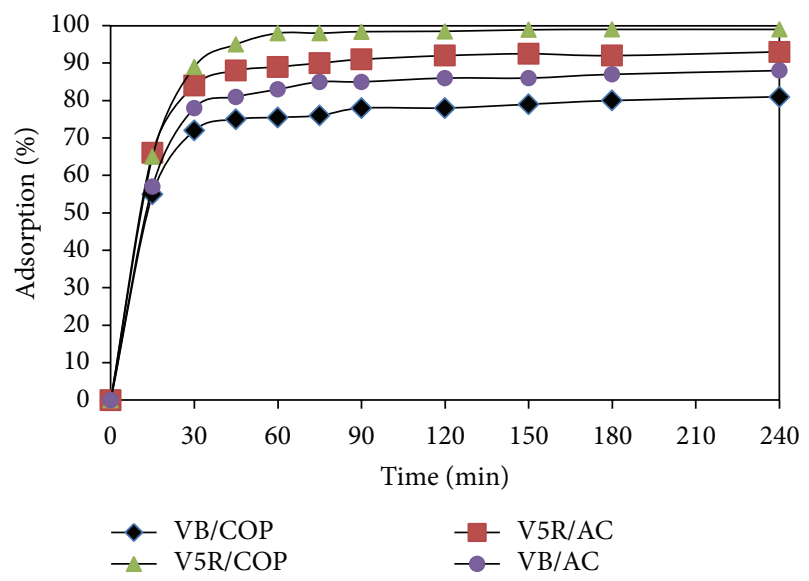

FIGURE 5: Effect of contact time on the removal of violet $\mathrm{B}$ and violet $5 \mathrm{R}$ onto COP.

and the solid phase when the adsorption process reaches an equilibrium state. Several models describe the adsorption process. The experimental data for COP adsorbing violet $\mathrm{B}$ and violet $5 \mathrm{R}$ could be fit by Langmuir and Freundlich isothermal models. The Langmuir model is in the linear form:

$$
\frac{C_{e}}{q_{e}}=\frac{1}{K_{L} q_{\max }}+\frac{C_{e}}{q_{\max }}
$$

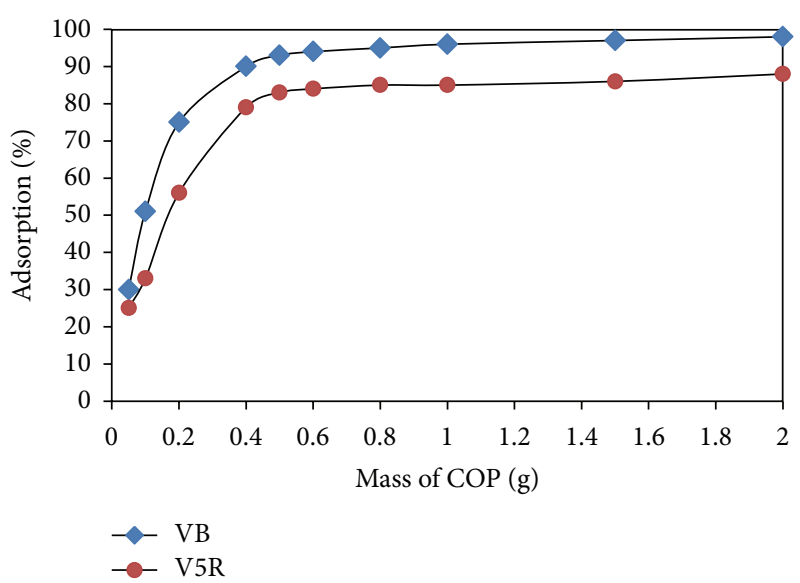

FIGURE 6: Effect of $\mathrm{pH}$ on adsorption of violet $\mathrm{B}$ and violet $5 \mathrm{R}$ onto $\mathrm{COP}\left(100 \mathrm{mg} \mathrm{L}^{-1}\right)$ at room temperature.

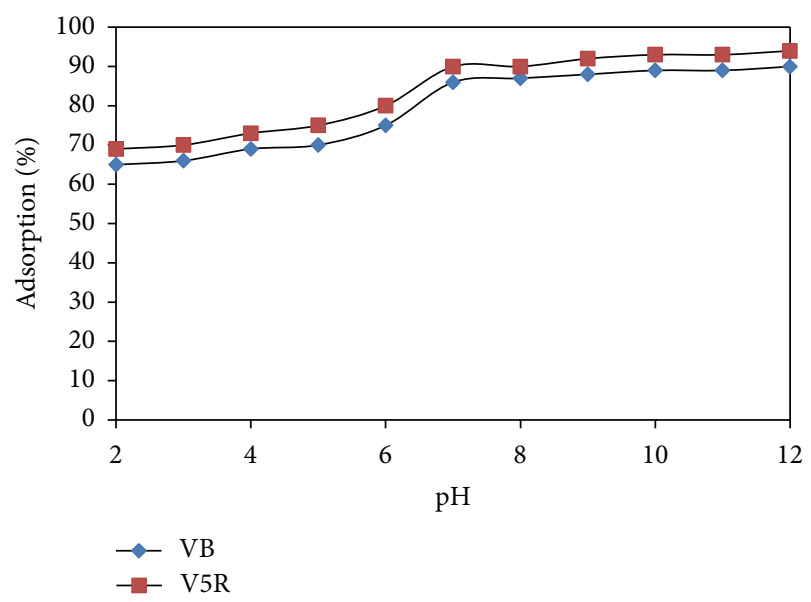

FIGURE 7: Effect of adsorbent mass on adsorption of violet $B$ and violet $5 \mathrm{R}\left(50 \mathrm{~mL}\right.$ of $\left.100 \mathrm{mg} \mathrm{L}^{-1}\right)$ onto COP.

where $q_{\max }\left(\mathrm{mg} \mathrm{g}^{-1}\right)$ represents the maximum amount of dye per unit weight of adsorbent to form a complete monolayer on the surface, $K_{L}$ is the equilibrium adsorption constant, $q_{e}$ is the amount of dye adsorbed by adsorbent at equilibrium, and $C_{e}$ is the equilibrium concentration of dyes. The linearized Freundlich model is

$$
\ln q_{e}=\ln k+\frac{1}{n} \ln C_{e},
$$

where $1 / n$ represents Freundlich intensity parameter and $K_{F}$ indicates the adsorption capacity of COP. Langmuir equation and Freundlich equation were fitted to the isotherm data as shown in Table 2. Langmuir isotherm shows better fitting model with higher correlation coefficient $\left(R^{2}>0.98\right)$ compared to Freundlich isotherm $\left(R^{2}<0.950\right)$. The high correlation coefficient of Langmuir isotherm indicates that dyes strongly adsorbed to the surface of COP. It is verified that COP has great potential to be a good adsorbent for the removal of dye in water treatment. Table 2 shows the Langmuir and Freundlich isotherm parameters for violet $\mathrm{B}$ and 
TABLE 2: Langmuir and Freundlich isotherm parameters for violet $\mathrm{B}$ and violet $5 \mathrm{R}$ adsorption onto COP.

\begin{tabular}{|c|c|c|c|c|c|c|}
\hline \multirow{2}{*}{ Sample } & \multicolumn{3}{|c|}{ Freundlich } & \multicolumn{3}{|c|}{ Langmuir } \\
\hline & $K_{F}$ & $n$ & $R^{2}$ & $q_{\max }\left(\mathrm{mg} \mathrm{g}^{-1}\right)$ & $K_{L}\left(\mathrm{~L} \mathrm{mg}^{-1}\right)$ & $R^{2}$ \\
\hline \multicolumn{7}{|l|}{ Violet B } \\
\hline $50 \mathrm{mg} \mathrm{L}^{-1}$ & 4.366 & 0.86 & 0.935 & 38.6 & 33.65 & 0.980 \\
\hline $100 \mathrm{mg} \mathrm{L}^{-1}$ & 4.47 & 0.91 & 0.862 & 42.5 & 35.32 & 0.975 \\
\hline $150 \mathrm{mg} \mathrm{L}^{-1}$ & 4.83 & 0.94 & 0.944 & 44.2 & 36.7 & 0.986 \\
\hline \multicolumn{7}{|l|}{ Violet 5R } \\
\hline $50 \mathrm{mg} \mathrm{L}^{-1}$ & 5.26 & 0.78 & 0.940 & 36.45 & 42.0 & 0.992 \\
\hline $100 \mathrm{mg} \mathrm{L}^{-1}$ & 5.34 & 0.82 & 0.880 & 36.96 & 43.4 & 0.995 \\
\hline $150 \mathrm{mg} \mathrm{L}^{-1}$ & 5.41 & 0.86 & 0.924 & 37.26 & 44.2 & 0.996 \\
\hline
\end{tabular}

violet $5 \mathrm{R}$ adsorption onto $\mathrm{COP}$. The results showed that the maximum adsorption capacity of COP was increased by increasing of adsorbent dosage from 0.1 to $1.0 \mathrm{~g}$. For violet $\mathrm{B}$ maximum adsorption capacity of $\mathrm{COP}$ was increased from $38.6 \mathrm{mg} \mathrm{g}^{-1}$ to $49.2 \mathrm{mg} \mathrm{g}^{-1}$ and for violet $5 \mathrm{R}$ from $52.45 \mathrm{mg} \mathrm{g}^{-1}$ to $87.26 \mathrm{mg} \mathrm{g}^{-1}$, respectively.

3.7. Adsorption Kinetics. The kinetic parameters give important information for designing and modeling of adsorption processes. Thus, pseudo-first-order [35] and pseudo-secondorder [36] kinetic models were studied for adsorption of violet $B$ and violet $5 R$ onto $C O P$. The conformity between experimental data and the model-predicted values was expressed by the correlation coefficients $\left(R^{2}\right.$, values close or equal to 1 , the relatively higher value is the more applicable model).

3.7.1. Pseudo-First-Order Equation. The adsorption kinetic data were described by the Lagergren pseudo-first-order model [35], which is the earliest known equation describing the adsorption rate based on the adsorption capacity. The Lagergren equation is commonly expresses as follows:

$$
\frac{d q_{t}}{d t}=k_{1}\left(q_{e}-q_{t}\right)
$$

where $q_{e}$ and $q_{t}$ are the adsorption capacity at equilibrium and at time $t$, respectively $\left(\mathrm{mg} \mathrm{g}^{-1}\right)$, and $k_{1}$ is the rate constant of pseudo-first order adsorption $\left(\mathrm{L} \mathrm{min}^{-1}\right)$.

Integrating (8) for the boundary conditions $t=0-t$ and $q_{t}=0-q_{t}$ and rearranging to obtain the following linear form gives the following equation:

$$
\log \left(q_{e}-q_{t}\right)=\log \left(q_{e}\right)-k_{1} \frac{t}{2.303} .
$$

Plot of values of $\log \left(q_{e}-q_{t}\right)$ versus $t$ to give a linear relationship from which $k_{1}$ and $q_{e}$ can be determined from the slope and intercept, respectively (Figure 8).

3.7.2. Pseudo-Second-Order Equation. The adsorption kinetic may be described by the pseudo-second-order model [36], which is generally given as follows

$$
\frac{d q_{t}}{d t}=k_{2}\left(q_{e}-q_{t}\right)^{2}
$$

where $k_{2}\left(\mathrm{~g} \mathrm{mg}^{-1} \mathrm{~min}^{-1}\right)$ is the second-order rate constant of adsorption. Integrating (10) for the boundary conditions $q_{t}=$ 0 to $q_{t}=q_{t}$ at $t=0$ to $t=t$ is simplified as can be rearranged and linearized to obtain the following equation:

$$
\frac{t}{q_{t}}=\frac{1}{\left(k_{2} q_{e}^{2}\right)}+\frac{t}{q_{e}}
$$

It was mentioned that the curve fitting plot of $\log \left(q_{e}-q_{t}\right)$ versus $t$ does not show good results for the entire sorption period (Figure 8 ), while the plot of $t / q_{t}$ versus $t$ gives a straight line as shown in Figure 9, confirming the applicability of the pseudo-second-order equation. Values of $k_{2}$ and equilibrium adsorption capacity $q_{e}$ were calculated from the intercept and slope of the plots of $t / q_{t}$ versus $t$, respectively. The values of $R^{2}$ and $q_{e}$ also indicated that this equation produced better results (Table 3). $R^{2}$ values for pseudo-second-order kinetic model were found to be higher (between 0.994 and 0.996), and the calculated $q_{e}$ values are mainly equal to the experimental data. This indicates that the adsorption system of COP obeys the pseudo-second-order kinetic model for the entire sorption period. Figures 8 and 9 show the pseudofirst-order and pseudo-second-order models of adsorption for $50 \mathrm{~mL}$ of $100 \mathrm{mg} \mathrm{L}^{-1}$ of violet $\mathrm{B}$ and violet $5 \mathrm{R}$ and $0.4 \mathrm{~g}$ of COP at room temperature. Table 3 also shows the kinetic parameters of adsorption of violet $B$ and violet $5 R$ dyes onto COP. It was observed that the pseudo-second order rate constant $\left(k_{2}\right)$ increased with increasing of temperature from $6.60 \times 10^{-5}$ to $7.60 \times 10^{-5}$ for VB and $1.965 \times 10^{-4}$ to $4.86 \times$ $10^{-4}$ for violet $5 \mathrm{R}$, respectively. Activation energies 5.47 and $29.7 \mathrm{KJ} \mathrm{mol}^{-1}$ were determined for violet $\mathrm{B}$ and violet $5 \mathrm{R}$, respectively. Results show that the adsorption of violet $5 \mathrm{R}$ is more favorable than VB onto COP.

3.8. Effect of Ionic Strength. The wastewaters released into the environment from different industries may contain various types of salts besides dyestuffs and that is why the effect of ionic strength upon the uptake of dye was studied by adding $\mathrm{KCl}, \mathrm{Na}_{2} \mathrm{SO}_{4}$, and $\mathrm{NaNO}_{3}$ solutions. In order to do some experiments, $50 \mathrm{~mL}$ of each dye and $100 \mathrm{mg} \mathrm{L}^{-1}$ at $\mathrm{pH} 12$ were used and $0.10 \mathrm{~g}$ adsorbent was added. The adsorption amount of azo dyes decreased with increasing of $\mathrm{KCl}$ and $\mathrm{NaNO}_{3}$ concentrations in the solution from 0.1 to $1 \mathrm{M}$. This can be explained by the fact that the cations $\left(\mathrm{K}^{+}\right.$and $\left.\mathrm{Na}^{+}\right)$ 
TABLE 3: Kinetics parameters for the removal of violet $\mathrm{B}$ and violet $5 \mathrm{R}$ by COP $\left(50 \mathrm{~mL}\right.$ of $100 \mathrm{mg} \mathrm{L}^{-1}$ of violet $\mathrm{B}$ and violet $5 \mathrm{R}$ and $0.4 \mathrm{~g}$ of COP at room temperature).

\begin{tabular}{lcccc}
\hline Sample & \multicolumn{3}{c}{ First order } & \multicolumn{2}{c}{ Second order } & $R^{2}$ & $k_{2}\left(\mathrm{~g} \mathrm{mg}^{-1} \mathrm{~min}^{-1}\right)$ \\
\hline VB & $R^{2}$ & $k_{1}\left(\mathrm{~s}^{-1}\right)$ & 0.994 & $6.6 \times 10^{-5}$ \\
V5R & 0.950 & $1.9 \times 10^{-5}$ & 0.996 & $1.965 \times 10^{-4}$ \\
\hline
\end{tabular}

TABLE 4: Comparison of maximum adsorption capacities of orange peel with different dyes.

\begin{tabular}{|c|c|c|c|c|c|}
\hline Name of pollutant & Maximum adsorption $\left(\mathrm{mg} \mathrm{L}^{-1}\right)$ & Reference & Name of pollutant & Maximum adsorption $\left(\mathrm{mg} \mathrm{L}^{-1}\right)$ & Reference \\
\hline Direct blue- 86 & 33.78 & {$[24]$} & Methyl violet & 11.5 & {$[28]$} \\
\hline Methylene blue & 18.6 & {$[28]$} & Amido black & 7.9 & {$[28]$} \\
\hline Rhodamine B & $14.3,3.23$ & {$[29,30]$} & Direct red 80 & 21.05 & {$[31,32]$} \\
\hline Congo red 14.0 & $14.0,22.4$ & {$[29,30]$} & Direct red 23 & 10.72 & {$[31,32]$} \\
\hline \multirow{2}{*}{ Acid violet 17} & \multirow{2}{*}{19.88} & \multirow{2}{*}[28,30]{} & Violet B & 49.2 & This study \\
\hline & & & Violet $5 \mathrm{R}$ & 87.26 & This study \\
\hline
\end{tabular}

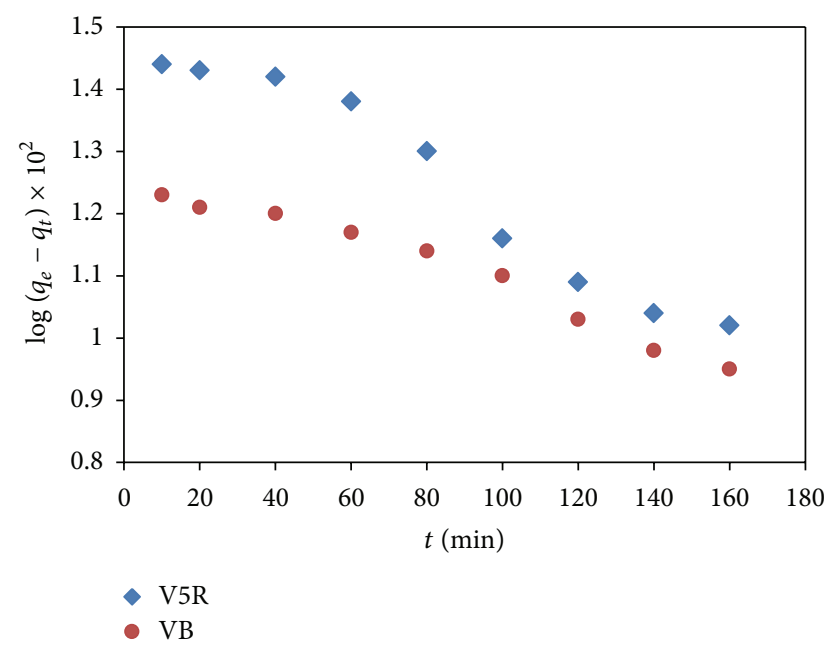

FIGURE 8: Pseudo-first-order kinetic model for violet B and violet $5 \mathrm{R}$ adsorption onto COP.

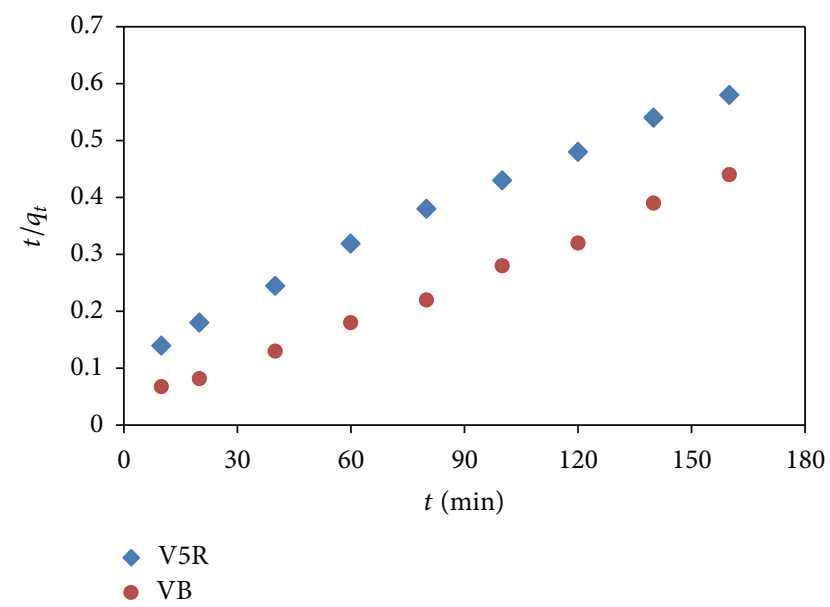

FIGURE 9: Pseudo-second-order kintic model for violet B and violet $5 \mathrm{R}$ adsorption onto COP. from the salts compete with dye ions for the active adsorption sites of COP so the electrostatic interactions between dyes and surface functional groups of COP, were impeded in the presence of ionic strength. On the other hand, the $\mathrm{Na}_{2} \mathrm{SO}_{4}$ salt causes an increase in the degree of dissociation of the dye molecules by facilitating the protonation. The adsorbed amount of dyes increased as the dissociated dye ions left free for binding electrostatically onto the oppositely charged COP surface $[37,38]$.

3.9. Desorption. The economic possibility of adsorbent is one of the major concerns among its applications. It is widely estimated by the reusability of adsorbent. The COP is simple to thermally regenerate and regeneration temperature is commonly at or beyond $500^{\circ} \mathrm{C}$. The good regeneration result and relatively low regeneration temperature demonstrated that the COP could offer high adsorptive activity. The adsorption capacity of the COP for dyes after its regeneration has also been studied. The regenerated samples of COP were again saturated with violet $B$ and violet $5 R$ with the same initial concentration of $100 \mathrm{mg} \mathrm{L}^{-1}$, determining their new adsorption capacity. Generally, the adsorption capacity of the COP decreases as the number of regeneration cycle increased.

Further, our experiment also displays that the adsorption capacity could maintain above $95 \%$ of its initial capability for violet $5 \mathrm{R}$ and $90 \%$ for violet $\mathrm{B}$ after five cycles and above $80 \%$ of its initial capability for violet $5 \mathrm{R}$ and $75 \%$ for violet $\mathrm{B}$ after 8 cycles. The result here illustrates that COP can be employed repeatedly for the removal of dyes.

3.10. Comparison of COP with Other Adsorbents. The comparison of maximum adsorption capacities of some dyes with orange peel is shown in Table 4. COP in this study possesses reasonable adsorption capacity in comparison with other sorbents. COP is inexpensive agricultural waste material with rapid rate and high adsorption capacity. It is also friendly environment sorbent. 


\section{Conclusions}

Low-cost activated carbon from orange peel was prepared as adsorbent for adsorption of azo dyes from aqueous solutions. Activated carbon developed from orange peel can be attractive options for dye removal from diluted industrial effluents. The results of this study can be summarized as follows: activated carbon developed from orange peel is a promising adsorbent for removal of the azo dye (violet $B$ and violet $5 \mathrm{R}$ ) from wastewater. A small amount $(0.4 \mathrm{mg} / 50 \mathrm{~mL})$ of COP could almost remove over $75 \%$ of $100 \mathrm{mg} \mathrm{L}^{-1}$ of violet $\mathrm{B}$ and violet $5 \mathrm{R}$ within 30 min contact time. The $\mathrm{pH}$ is important in the controlling of adsorption. The Langmuir and Freundlich adsorption models were used to express the sorption phenomenon of azo dyes. The data obtained were in good agreement with the Langmuir isotherm model. The kinetic study of violet $B$ and violet $5 \mathrm{R}$ on $\mathrm{COP}$ was investigated using pseudofirst-order and pseudo-second-order equations. The results indicate that the adsorption kinetics follow the pseudosecond-order rate and $k_{2(\mathrm{~V} 5 \mathrm{R})}>k_{2(\mathrm{VB})}$. The used COP could be regenerated. The result illustrates that COP can be employed repeatedly after 8 cycles for the removal of dyes. It can be concluded that COP may possess a potential application in violet $\mathrm{B}$ and violet $5 \mathrm{R}$ adsorption. The present study concludes that the COP could be employed as low-cost adsorbent as alternative to commercial activated carbon for the removal of color and dyes from water and wastewater in general and for the removal of azo dyes.

\section{References}

[1] S. Hashemian and A. Forighimoghadam, "Effect of copper doping on $\mathrm{CoTiO}_{3}$ ilmenite type nanoparticles for removal of congo red from aqueous solution," Chemical Engineering Journal, vol. 235, pp. 299-306, 2014.

[2] G. McKay, "Adsorption of dyestuffs from aqueous solutions with activated carbon-1. equilibrium and batch contact-time studies," Journal of Chemical Technology and Biotechnology, vol. 32, no. 8, pp. 759-772, 1982.

[3] P. Nigam, I. M. Banat, D. Singh, and R. Marchant, "Microbial process for the decolorization of textile effluent containing azo, diazo and reactive dyes," Process Biochemistry, vol. 31, no. 5, pp. 435-442, 1996.

[4] V. K. Gupta and S. Suhas, "Application of low-cost adsorbents for dye removal-a review," Journal of Environmental Management, vol. 90, no. 8, pp. 2313-2342, 2009.

[5] P. Velmurugan, V. Rathinakumar, and G. Dhinakaran, "Dye removal from aqueous solution using low cost adsorbent," International Journal of Environmental Sciences, vol. 1, no. 7, pp. 1492-1503, 2011.

[6] M. M. Sundaram and S. Sivakumar, "Use of indian almond shell waste and groundnut shell waste for the removal of azure a dye from aqueous solution," Journal of Chemical and Pharmaceutical Research, vol. 4, no. 4, pp. 2047-2054, 2012.

[7] M. Aliabadi, I. Khazaei, M. Hajiabadi, and S. Fazel, "Removal of rhodamine B from aqueous solution by almond shell biosorbent," Journal of Biodiversity and Environmental Sciences, vol. 2, no. 9, pp. 39-44, 2012.

[8] B. K. Singh and N. S. Rawat, "Comparative sorption equilibrium studies of toxic phenols on flyash and impregnated flyash,"
Journal of Chemical Technology and Biotechnology, vol. 61, no. 4, pp. 307-317, 1994.

[9] S. Hong and C. Ning, "Adsorption of Cr(VI) on Fe-Ni modified bentonites," Environmental Engineering and Management Journal, vol. 10, no. 7, pp. 875-879, 2011.

[10] M. H. Koppelman and J. G. Dillard, "A study of the adsorption of $\mathrm{Ni}(\mathrm{II})$ and $\mathrm{Cu}(\mathrm{II})$ by clay minerals," Clays and Clay Minerals, vol. 25, no. 6, pp. 457-462, 1977.

[11] S. Hashemian, "Removal of acid red 151 from water by adsorption onto nano-composite $\mathrm{MnFe}_{2} \mathrm{O}_{4}$ /kaolin," Main Group Chemistry, vol. 10, no. 2, pp. 105-114, 2011.

[12] S. Hashemian, " $\mathrm{MnFe}_{2} \mathrm{O}_{4}$ /bentonite nano composite as a novel magnetic material for adsorption of acid red 138," African Journal of Biotechnology, vol. 9, no. 50, pp. 8667-8671, 2010.

[13] S. Hashemian and M. Mirshamsi, "Kinetic and thermodynamic of adsorption of 2-picoline by sawdust from aqueous solution," Journal of Industrial and Engineering Chemistry, vol. 18, pp. 2010-2015, 2012.

[14] S. Hashemian, "Modified sawdust for removal of methyl violet (basic dye) from aqueous solutions," Asian Journal of Chemistry, vol. 21, no. 5, pp. 3622-3630, 2009.

[15] A. Habib, N. Islam, and A. M. S. Alam, "Removal of copper from aqueous solution using orange peel, sawdust and bagasse," Pakistan Journal of Analytical and Environmental Chemistry, vol. 8, no. 2, pp. 21-25, 2007.

[16] A. E. Ofomaja, "Kinetic study and sorption mechanism of methylene blue and methyl violet onto mansonia (Mansonia altissima) wood sawdust," Chemical Engineering Journal, vol. 143, no. 1-3, pp. 85-95, 2008.

[17] D. H. Lataye, I. M. Mishra, and I. D. Mall, "Pyridine sorption from aqueous solution by rice husk ash (RHA) and granular activated carbon (GAC): parametric, kinetic, equilibrium and thermodynamic aspects," Journal of Hazardous Materials, vol. 154, no. 1-3, pp. 858-870, 2008.

[18] D. Mohan, K. P. Singh, S. Sinha, and D. Gosh, "Removal of pyridine derivatives from aqueous solution by activated carbons developed from agricultural waste materials," Carbon, vol. 43, no. 8, pp. 1680-1693, 2005.

[19] J. M. Salman, V. O. Njoku, and B. H. Hameed, "Adsorption of pesticides from aqueous solution onto banana stalk activated carbon," Chemical Engineering Journal, vol. 174, no. 1, pp. 41-48, 2011.

[20] I. Bhatti, K. Qureshi, R. A. Kazi, and A. K. Ansari, "Preparation and characterization of chemically activated almond shell by optimization of adsorption parameters for removal of chromium (VI) from aqueous solution," International Journal of Chemical and Biological Engineering, vol. 1, no. 3, pp. 149-154, 2008.

[21] A. Khaled, A. E. Nemr, A. El-Sikaily, and O. Abdelwahab, "Removal of Direct N Blue-106 from artificial textile dye effluent using activated carbon from orange peel: adsorption isotherm and kinetic studies," Journal of Hazardous Materials, vol. 165, no. 1-3, pp. 100-110, 2009.

[22] G. Annadurai, R. S. Juang, and D. J. Lee, "Adsorption of heavy metals from water using banana and orange peels," Water Science and Technology, vol. 47, no. 1, pp. 185-190, 2003.

[23] W. Shan, D. Fang, Z. Zhao et al., "Application of orange peel for adsorption separation of molybdenum(VI) from Re-containing industrial effluent," Biomass and Bioenergy, vol. 37, pp. 289-297, 2012. 
[24] A. E. Nemr, O. Abdelwahab, A. El-Sikaily, and A. Khaled, "Removal of direct blue- 86 from aqueous solution by new activated carbon developed from orange peel," Journal of Hazardous Materials, vol. 161, no. 1, pp. 102-110, 2009.

[25] S. Liang, X. Guo, N. Feng, and Q. Tian, "Application of orange peel xanthate for the adsorption of $\mathrm{Pb}^{2+}$ from aqueous solutions," Journal of Hazardous Materials, vol. 170, no. 1, pp. 425429, 2009.

[26] M. Deraman, I. A. Talib, M. Ramli Omar, H. H. J. Jumali, E. Taer, and M. M. Saman, "Microcrystallite dimension and total active surface area of carbon electrode from mixtures of PreCarbonized oil palm empty fruit bunches and green petroleum cokes," Sains Malaysiana, vol. 39, no. 1, pp. 83-86, 2010.

[27] K. Kumar, R. K. Saxena, R. Kothari, D. K. Suri, N. K. Kaushik, and J. N. Bohra, "Correlation between adsorption and X-ray diffraction studies on viscose rayon based activated carbon cloth," Carbon, vol. 35, no. 12, pp. 1842-1844, 1997.

[28] G. Annadurai, R.-S. Juang, and D.-J. Lee, "Use of cellulose-based wastes for adsorption of dyes from aqueous solutions," Journal of Hazardous Materials, vol. 92, no. 3, pp. 263-274, 2002.

[29] C. Namasivayam, N. Muniasamy, K. Gayatri, M. Rani, and K. Ranganathan, "Removal of dyes from aqueous solutions by cellulosic waste orange peel," Bioresource Technology, vol. 57, no. 1, pp. 37-43, 1996.

[30] R. Sivaraj, C. Namasivayam, and K. Kadirvelu, "Orange peel as an adsorbent in the removal of Acid violet 17 (acid dye) from aqueous solutions," Waste Management, vol. 21, no. 1, pp. 105110, 2001.

[31] M. Arami, N. Y. Limaee, N. M. Mahmoodi, and N. S. Tabrizi, "Removal of dyes from colored textile wastewater by orange peel adsorbent: equilibrium and kinetic studies," Journal of Colloid and Interface Science, vol. 288, no. 2, pp. 371-376, 2005.

[32] F. Doulati Ardejani, K. Badii, N. Yousefi Limaee et al., "Numerical modelling and laboratory studies on the removal of Direct Red 23 and Direct Red 80 dyes from textile effluents using orange peel, a low-cost adsorbent," Dyes and Pigments, vol. 73, no. 2, pp. 178-185, 2007.

[33] S. Hashemian, "Kinetic and thermodynamic of adsorption of methylene blue (MB) by $\mathrm{CuFe}_{2} \mathrm{O}_{4}$ /rice bran composite," International Journal of Physical Sciences, vol. 6, no. 27, pp. 62576267, 2011.

[34] S. Hashemian and M. Salimi, "Nano composite a potential low cost adsorbent for removal of cyanine acid," Chemical Engineering Journal, vol. 188, pp. 57-63, 2012.

[35] S. Lagergren, "Zur theorie der sogenannten adsorption geloster stoffe Kungliga Svenska Vetenskapsakademiens," Handlingar, vol. 24, pp. 1-39, 1898.

[36] Y. S. Ho, G. McKay, D. A. J. Wase, and C. F. Forster, "Study of the sorption of divalent metal ions on to peat," Adsorption Science and Technology, vol. 18, no. 7, pp. 639-650, 2000.

[37] M. Doğan, Y. Özdemir, and M. Alkan, "Adsorption kinetics and mechanism of cationic methyl violet and methylene blue dyes onto sepiolite," Dyes and Pigments, vol. 75, no. 3, pp. 701-713, 2007.

[38] D. Ozdes, A. Gundogdu, C. Duran, and H. B. Senturk, "Evaluation of adsorption characteristics of malachite green onto almond shell (prunus dulcis)," Separation Science and Technology, vol. 45, no. 14, pp. 2076-2085, 2010. 

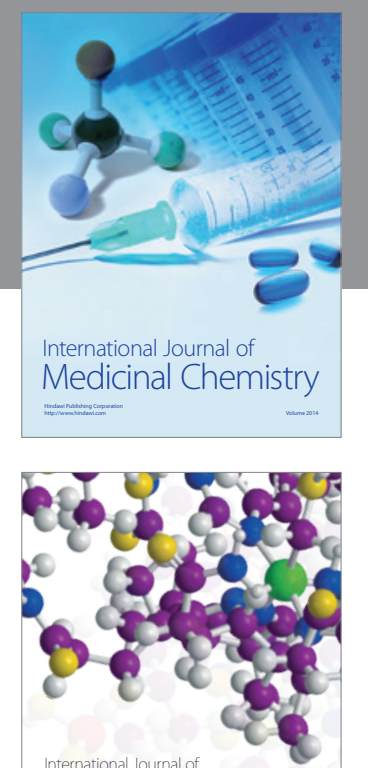

\section{Carbohydrate} Chemistry

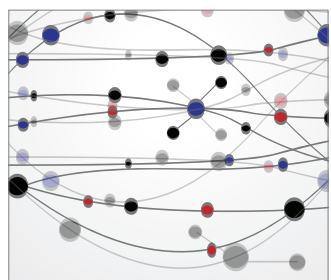

The Scientific World Journal
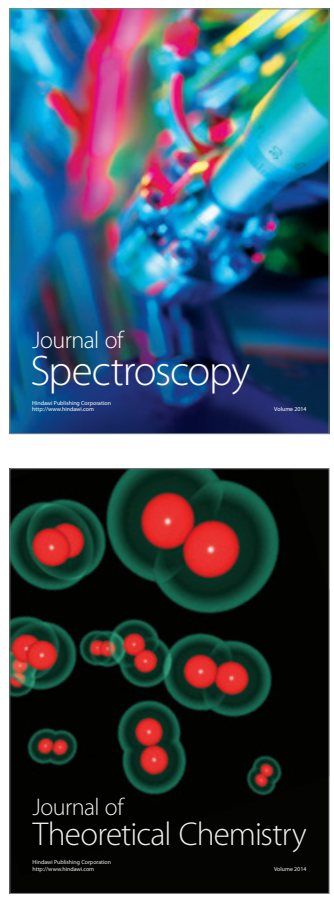
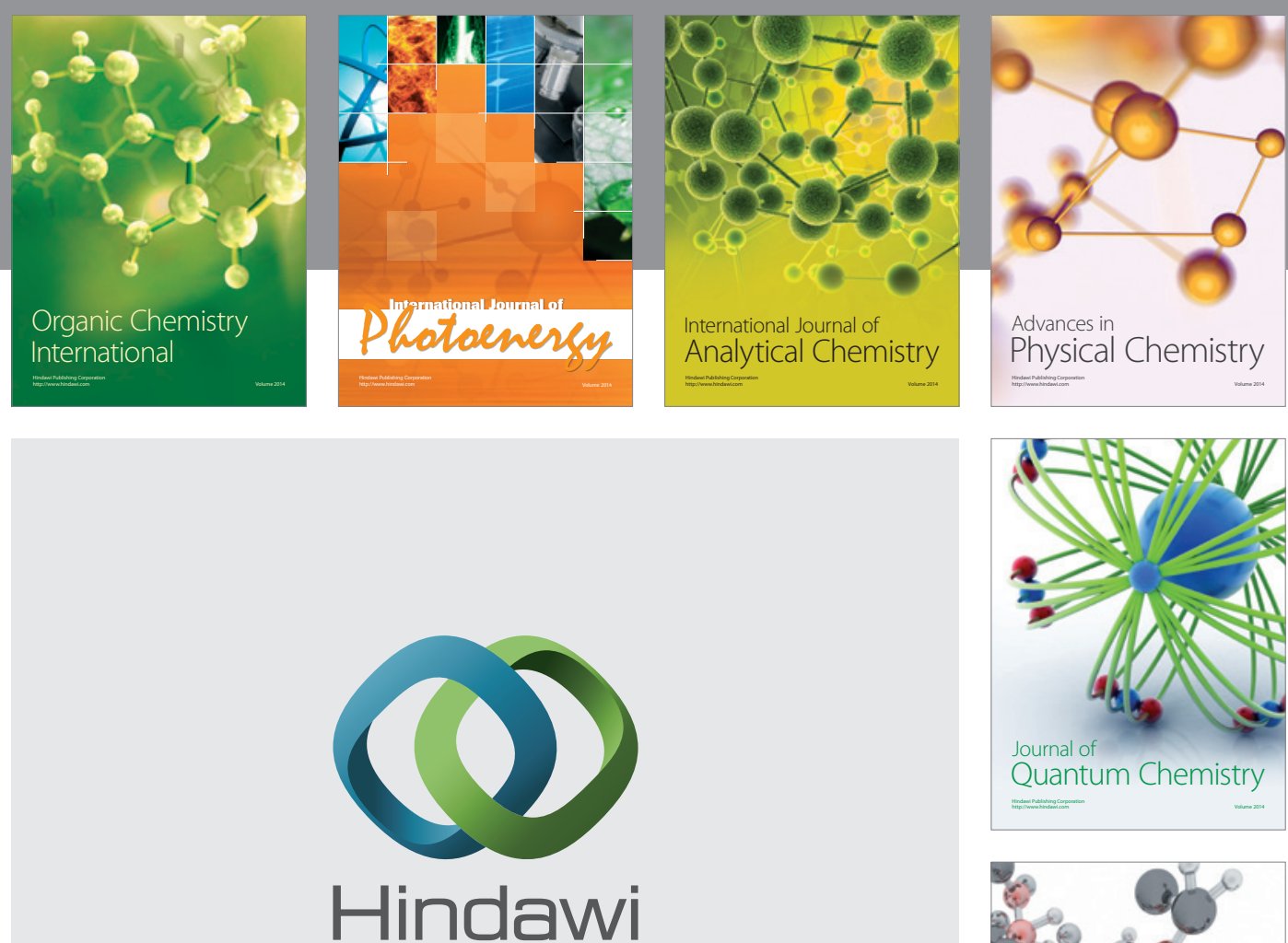

Submit your manuscripts at

http://www.hindawi.com

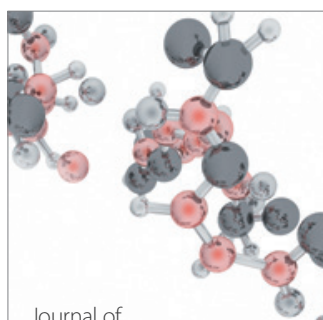

Analytical Methods

in Chemistry

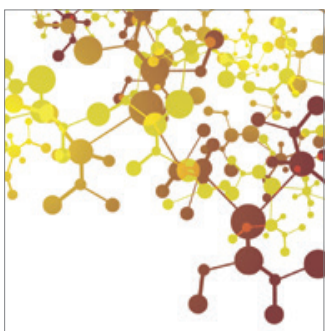

Journal of

Applied Chemistry

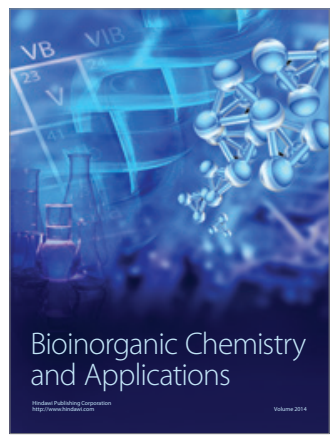

Inorganic Chemistry
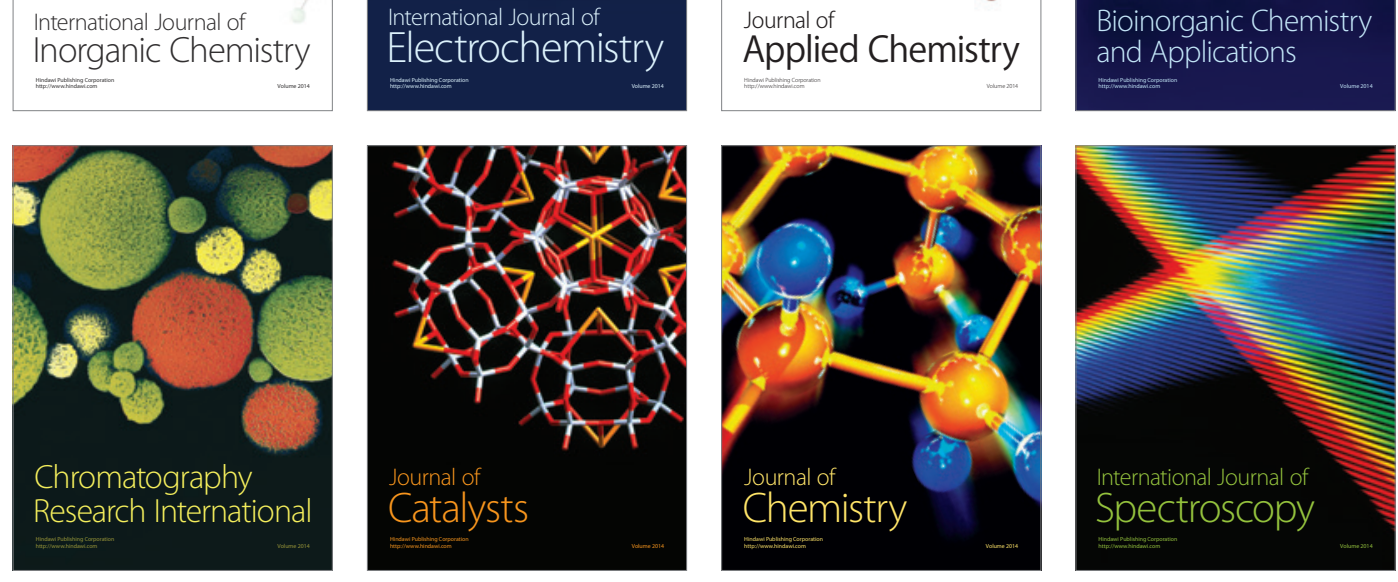